Ege Tıp Dergisi / Ege Journal of Medicine 2021; 60 (1): 51-57

\title{
Diagnostik histeroskopi ve endometrial biyopsi ile embriyo transferi arası geçen süre gebelik sonuçları üzerine etkili midir?
}

\author{
Does the time interval between diagnostic hysteroscopy with endometrial \\ biopsy and embryo transfer affect pregnancy outcome?

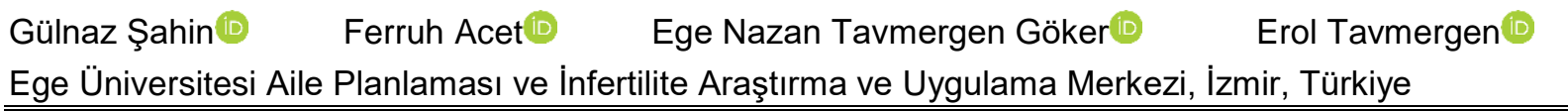

Öz

Amaç: In vitro fertilizasyon öncesi diagnostik histeroskopi ve endometrial hasar oluşturmanın etkinliği birçok çalışmada araştırılmıştır ve sonuçlar tartışmalıdır. Prosedürler arası optimal zaman aralığı ve optimal endometrial hasar oluşturma tekniği de net olarak tanımlanmamıştır. Bu çalışmanın amacı histeroskopi/endometrial biyopsi ile embriyo transferi arası zaman aralığının reprodüktif sonuçlar üzerine etkisini araştırmaktır.

Gereç ve Yöntem: 2016-2018 yılları arasında, in vitro fertilizasyon siklusu öncesinde diagnostik histeroskopiyle birlikte endometrial biyopsi yapılan olgular retrospektif olarak analiz edildi. Hastalar prosedürler arası süreye göre beş gruba ayrıldı. Grupların reprodüktif sonuçları olarak klinik gebelik, gebelik kaybı ve canlı doğum oranları analiz edildi.

Bulgular: Toplamda 252 hasta analize alındı, \%49,2'si tekrarlayan implantasyon başarısızlığı olan olguları içeriyordu. Embriyo transfer siklusu olguların \%29'unda histeroskopi/endometrial biyopsi prosedüründen 1 ay sonra, \%32'sinde 2 ay sonra, \%17,5'unda 3-4 ay sonra, \%12'sinde 5-6 ay sonra ve \%9,5'unda 6 aydan daha geç sürede uygulandı. Grupların temel karakteristikleri farklııı göstermiyordu. Grupların klinik gebelik $(\% 34,2, \% 35,8, \% 31,8, \% 40$ ve $\% 37,5)$, gebelik kaybı (\%8,2, $\% 8,6, \% 9,1, \% 13,3$ ve $\% 8,3$ ) ve canlı doğum oranları $(\% 26, \% 27,2, \% 22,7, \% 26,7$ ve $\% 29,2)$ benzer olarak saptandı.

Sonuç: Diagnostik histeroskopi/endometrial biyopsi ile embriyo transfer uygulaması arası geçen süre açısından reprodüktif sonuçlarda bir farklılık bulunmamaktadır. IVF-embriyo transferini ertesi menstrüel siklusta veya daha geç yapmak sonuçları etkilemeyebilir.

Anahtar Sözcükler: Histeroskopi, IVF, embriyo transfer, klinik gebelik, canlı doğum.

\begin{abstract}
Aim: The effectiveness of diagnostic hysteroscopy and endometrial injury prior to the in vitro fertilization cycle has been examined in several studies with conflicting results. The optimal time interval for the procedures and the technique for endometrial injury have not described yet. The aim of this study is to investigate the effect of the time interval between hysteroscopy/endometrial biopsy procedure and embryo transfer on reproductive outcomes.
\end{abstract}

Materials and Methods: Patients who underwent diagnostic H/S and endometrial biopsy procedure prior to the in vitro fertilization cycle, between 2016-2018 years, were retrospectively analyzed. Patients were divided into 5 groups according to the time interval between the procedures. Reproductive outcomes as clinical pregnancy rates, pregnancy loss rates, and live birth rates of the groups were analyzed.

\footnotetext{
Sorumlu yazar: Gülnaz Şahin

Ege Üniversitesi Aile Planlaması ve İnfertilite Araştırma ve

Uygulama Merkezi, İzmir, Türkiye

E-posta: gsahini@msn.com

Başvuru tarihi: 07.08.2020 Kabul tarihi: 01.12.2020
} 
Results: A total of 252 patients were included to the analysis and $49.2 \%$ consisted of patients with repeated implantation failure. Totally 29\% of the embryo transfer cycle was performed after one 1 month, 32\% after 2 months, 17.5\% after 3-4 months, 12\% after 5-6 months and 9.5\% after more than 6 months of the hysteroscopy/endometrial biopsy procedure. The baseline characteristics were not different between the groups. The clinical pregnancy $(34.2 \%, 35.8 \%, 31.8 \%, 40 \%$ and $37.5 \%$, respectively), pregnancy loss rate (\%8.2, \%8.6, \%9.1, \%13.3 ve \%8.3)_and live birth rates (26\%, $27.2 \%, 22.7 \%, 26.7 \%$ and $29.2 \%$, respectively) were similar of the groups.

Conclusion: There is no significant difference in reproductive outcomes according to the time interval between diagnostic hysteroscopy/endometrial biopsy and embryo transfer procedures. Performing IVF-embryo transfer in the next menstrual cycle or later may not affect the outcomes.

Keywords: Hysteroscopy, IVF, embryo transfer, clinical pregnancy, live birth.

\section{GiRiş}

Yardımcı üreme tekniklerinde (YÜT) embriyonun implantasyonu gebelik sonuçları açısından kritik bir basamaktır. Günümüzde preimplantasyon genetik tanı gibi ileri tekniklerle gebelik açısından yüksek şanslı, kromozomal olarak normal embriyonun seçilebilmesine rağmen halen implantasyon aşaması hız sınırlayıcı bir rol oynamaktadır. Embriyonun endometriuma sağlıklı biçimde implantasyonunda rol oynayan mekanizmalar halen bütünüyle tanımlanamamıştır.

Yardımcı üreme teknikleri öncesinde, özellikle uterus kavitesine ilişkin şüpheli patoloji varlığında tanısal ve terapötik açıdan histeroskopi uygulanması altın standarttır (1). Uterus kavitesinin direkt gözlenmesiyle birlikte implantasyon üzerine olumsuz etkisi olabilecek submukoz myom, polip, adezyon gibi patolojilerin aynı zamanda tedavisi mümkün olabilmektedir. Tekrarlayan implantasyon başarısızlığı olan olgular için de uterus kavitesinin yeni bir transfer siklusu öncesinde histeroskopi ile tekrar değerlendirilmesi klinik pratikte yaygın olan bir yaklaşımdır.

İlk in vitro fertilizasyon (IVF) siklusu öncesinde veya tekrarlayan başarısız implantasyonu olan grupta rutin histeroskopi ve/veya endometrial hasar oluşturma yöntemlerinin reprodüktif sonuçlar üzerine etkinliği üzerine çalışmaların topluca değerlendirildiği güncel meta-analizler yayınlanmıştır (2-9). Endometrial hasarın, doku iyileşmesinde rol oynayan immun hücrelerin alana toplanması ve ilişkili sitokinler, büyüme faktörleri, makrofajlar ve dendritik hücreler yoluyla implantasyonda etkili olabileceği hipotezi öne sürülmüştür $(10,11)$. Günümüzde endometrial hasar oluşturmanın reprodüktif sonuçlar üzerine katkısıyla ilgili görüşler halen tartışmalıdır. Ek olarak endometrial hasar için uygulanan teknik ve derecesi ile ilgili standart bir yaklaşım bulunmamaktadır. Prosedürler ile embriyo transferi arası optimal süre konusunda da yeterli veri yoktur.

$\mathrm{Bu}$ çalışmada amacımız embriyo transferi (ET) öncesi uterus kavitesi ve endometrium değerlendirilmesi amacıyla tanısal histeroskopi $(\mathrm{H} / \mathrm{S})$ yanı sıra probe küretaj $(\mathrm{P} / \mathrm{C})$ yoluyla endometrial biyopsi yapılan olgularda uygulamalar arası geçen sürenin gebelik sonuçlarına etkisini araştırmaktır.

\section{GEREÇ VE YÖNTEM}

Çalışmamızda 2016-2018 yılları arasında Ege Üniversitesi Aile Planlaması ve İnfertilite Araştırma ve Uygulama Merkezi'nde embriyo transferi öncesinde tanısal histeroskopiyle birlikte probe küretaj uygulanarak endometrial örnekleme yapılan infertil olguların dosya verileri retrospektif olarak tarandı. Çalışma için Ege Üniversitesi Etik Kurul onayı alınmıştır. Çalışmaya 19-42 yaş aralığında, tekrarlayan implantasyon başarısızlığı veya diğer tanısal testlerde endometrial patoloji şüphesi nedeniyle $\mathrm{H} / \mathrm{S}$ ve P/C yapılan olgular dahil edildi. Tekrarlayan implantasyon başarısızlığı olan grup, öyküde en az iki siklus embriyo transferine rağmen gebelik elde edilemeyen olgular olarak tanımlandı. Operatif histeroskopi gerektiren olgular ile belirgin uterus anomalili olgular çalışma dışı bırakıldılar. Çalışmaya dahil edilen olguların H/S endikasyonları, yaş, infertilite süresi, infertilite etiyolojisi, varsa önceki IVF uygulamalarında transfer edilen embriyo sayıları, $\mathrm{H} / \mathrm{S}$ 'den sonra embriyo transferine kadar geçen süre (ay) ve embriyo transferi sonrası reprodüktif sonuçları kaydedildi.

Analizler için prosedürler arası süre sırasıyla 1, 2, $3-4, \quad 5-6$ ve $>6$ ay olarak gruplandırıldı. İstatistiksel değerlendirme SPSS 16.0 programı 
ile yapıldı. İstatistiksel analizde grupların karşılaştırılmasında kategorik değişkenler için kikare testi ile ve sayısal değişkenler için Anova test ve Kruskal-Wallis testleri kullanıldı. P değeri $<0,05$ istatistiksel olarak anlamlı kabul edildi.

\section{BULGULAR}

Toplamda 252 infertil olguya embriyo transferi öncesi tanısal H/S ve P/C uygulandı. H/S endikasyonları sırasıyla; tekrarlayan implantasyon başarısızlığı $(\% 49,2)$, histerosalpingografi (HSG) veya salin infüzyon sonografide (SiS) endometrial patoloji şüphesi $(\% 37,3)$ ve diğer nedenler $(\% 13,5)$ idi. Olguların IVF endikasyonları ise sırasıyla; $\% 40,1$ erkek faktörü, \%32,9 idiopatik infertilite, \%19 ovulatuar problem, \%7,1 tubal faktör, \%0,8 diğer nedenler olarak sıralandı. Çalışmamızda ele alınan grupların ortalama yaş, infertilite süreleri ve IVF endikasyonları dağılımları açısından benzerdi (Tablo-1).
Gruplar içinde tekrarlayan implantasyon başarısızlığı en sık H/S endikasyonu idi ve gruplar H/S endikasyon dağılımları açısından benzerlik gösteriyordu. Yanı sıra gruplar önceki embriyo transfer siklus sayıları ve H/S öncesi ve sonrası transfer edilen embriyo sayıları açısından da benzer idiler (Tablo-2).

\section{H/S ve endometrial biyopsi sonuçları}

Toplamda olguların \%66,7'sinde H/S ile gözlem ve endometrial örneklerin histopatolojik inceleme sonucu normal olarak saptandı. Olguların $\% 26,2$ 'sinde $(n=66)$ endometrial mikro/makro polipler, \%4'ünde $(n=10)$ dismorfik uterus (arkuat/T şekilli), \%3,2'sinde diğer patolojiler (kr.endometrit $n=4$, myom $n=2$, plasental bölge nodülü $n=1$ ve internal os sineşi $n=1$ ) saptandı. H/S bulgularının gruplara göre dağılımları istatistiksel olarak anlamlı farklılık göstermiyordu (Şekil-1).

Tablo-1. Olguların gruplara göre demografik özellikleri.

\begin{tabular}{|c|c|c|c|c|c|c|}
\hline & $\begin{array}{l}1 \text { ay } \\
(n=73)\end{array}$ & $\begin{array}{l}2 \text { ay } \\
(n=81)\end{array}$ & $\begin{array}{l}3-4 \text { ay } \\
(n=44)\end{array}$ & $\begin{array}{l}5-6 \text { ay } \\
(n=30)\end{array}$ & $\begin{array}{l}>6 \text { ay } \\
(n=24)\end{array}$ & $P$ \\
\hline Yaş (ort. $\pm S D)$ & $33,2 \pm 4,6$ & $32,5 \pm 4,6$ & $33 \pm 4,8$ & $33,9 \pm 4,3$ & $32,1 \pm 4,0$ & 0,59 \\
\hline $\begin{array}{l}\text { İnfertilite süresi ort. (min.- } \\
\text { maks.) }\end{array}$ & $6(1-15)$ & $5(1-20)$ & $5(1-19)$ & $5(1-18)$ & $5(2-20)$ & 0,99 \\
\hline \multicolumn{7}{|l|}{ İnfertilite nedeni (\%) } \\
\hline Erkek & 38,4 & 39,5 & 43,2 & 30 & 54,2 & 0,35 \\
\hline İdiopatik & 30,1 & 28,4 & 38,6 & 40 & 37,5 & \\
\hline Ovulatuar & 19,2 & 24,7 & 11,4 & 23,3 & 8,3 & \\
\hline Tubal & 12,3 & 4,9 & 6,8 & 6,7 & 0 & \\
\hline
\end{tabular}

Ort. = ortalama

Tablo-2. Grupların H/S endikasyonları ve IVF-ET siklus verileri.

\begin{tabular}{|c|c|c|c|c|c|c|}
\hline & 1 ay & 2 ay & 3-4 ay & 5-6 ay & $>6$ ay & $\boldsymbol{P}$ \\
\hline H/S endikasyonları \% & & & & & & 0.21 \\
\hline $\begin{array}{r}\text { Tekrarlayan implant. } \\
\text { başarısızlığı }\end{array}$ & 46,6 & 54,3 & 56,8 & 40 & 37,5 & \\
\hline $\begin{array}{r}\text { HSG veya SiS'de patoloji } \\
\text { şüphesi }\end{array}$ & 41,1 & 33,3 & 22,7 & 53,3 & 45,8 & \\
\hline Diğer & 12,3 & 12,3 & 20,5 & 6,7 & 16,7 & \\
\hline $\begin{array}{l}\text { H/S öncesi embriyo transfer } \\
\text { siklus sayısı (n) }\end{array}$ & $1,1 \pm 1,1$ & $1,4 \pm 1,1$ & $1,4 \pm 1$ & $1 \pm 1$ & $1,3 \pm 1,4$ & 0,6 \\
\hline $\begin{array}{l}\text { H/S öncesi transfer edilen } \\
\text { embriyo sayısı (n) }\end{array}$ & $1,6 \pm 1,9$ & $1,9 \pm 1,7$ & $1,9 \pm 1,8$ & $1,5 \pm 1,7$ & $1,8 \pm 2,5$ & 0,56 \\
\hline $\begin{array}{l}\text { H/S sonrası transfer edilen } \\
\text { embriyo sayısı ( } n)\end{array}$ & $1,5 \pm 0.5$ & $1,6 \pm 0,4$ & $1,6 \pm 0,4$ & $1,5 \pm 0,5$ & $1,5 \pm 0,5$ & 0,47 \\
\hline
\end{tabular}


Tablo-3. Grupların gebelik oranları.

\begin{tabular}{cllll}
\hline & $\begin{array}{l}\text { hCG pozitifliği } \\
\%, \mathbf{n}\end{array}$ & $\begin{array}{l}\text { Klinik gebelik } \\
\%, \mathbf{n}\end{array}$ & $\begin{array}{l}\text { Gebelik kaybı } \\
\%, \mathbf{n}\end{array}$ & $\begin{array}{l}\text { Canlı doğum } \\
\%, \mathbf{n}\end{array}$ \\
\hline 1 ay $(\mathrm{n}=73)$ & $37(27)$ & $34,2(25)$ & $8,2(6)$ & $26(19)$ \\
2 ay $(\mathrm{n}=81)$ & $40,7(33)$ & $35,8(29)$ & $8,6(7)$ & $27,2(22)$ \\
3-4 ay $(\mathrm{n}=44)$ & $31,8(14)$ & $31,8(14)$ & $9,1(4)$ & $22,7(10)$ \\
$5-6$ ay $(\mathrm{n}=30)$ & $40(12)$ & $40(12)$ & $13,3(4)$ & $26,7(8)$ \\
$>6$ ay $(\mathrm{n}=24)$ & $37,5(9)$ & $37,5(9)$ & $8,3(2)$ & $29,2(7)$ \\
\multicolumn{1}{c}{$P$} & 0,90 & 0,96 & 0,94 & 0,98 \\
\hline
\end{tabular}

Tablo-4. Tekrarlayan implantasyon başarısızığı olgularında grupların gebelik oranları.

\begin{tabular}{lllll}
\hline & hCG pozitifliği & $\begin{array}{l}\text { Klinik gebelik } \\
\%, \mathbf{n}\end{array}$ & $\begin{array}{l}\text { Gebelik kaybı } \\
\%, \mathbf{n}\end{array}$ & $\begin{array}{l}\text { Canlı doğum } \\
\%, \mathbf{n}\end{array}$ \\
\hline 1 ay $(\mathrm{n}=34)$ & $44,1(15)$ & $44,1(15)$ & $14,7(5)$ & $29,4(10)$ \\
2 ay $(\mathrm{n}=44)$ & $43,2(19)$ & $36,4(16)$ & $2,3(1)$ & $34,1(15)$ \\
3-4 ay $(\mathrm{n}=25)$ & $32(8)$ & $32(8)$ & $12(3)$ & $20(5)$ \\
$5-6$ ay $(\mathrm{n}=12)$ & $41,7(5)$ & $41,7(5)$ & $0(0)$ & $41,7(5)$ \\
$>6$ ay $(\mathrm{n}=9)$ & $33,3(3)$ & $33,3(3)$ & $0(0)$ & $33,3(3)$ \\
\multicolumn{1}{c}{$P$} & 0,86 & 0,89 & 0,14 & 0,67 \\
\hline
\end{tabular}

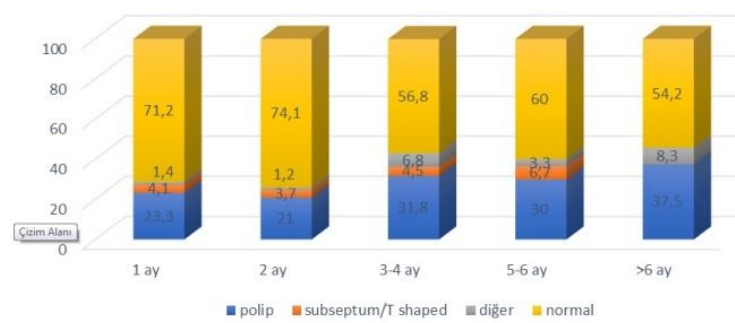

Şekil-1. Grupların H/S sonuçları.

Tekrarlayan implantasyon başarısızlığı nedeniyle $\mathrm{H} / \mathrm{S}$ ve $\mathrm{P} / \mathrm{C}$ ile endometrial biyopsi yapılan 124 olgu ayrıca ele alındığında bu olguların $\% 75,8^{\prime}$ inde (94 olgu) H/S sonucunda bir patoloji saptanmazken, \%20,9'unda (26 olgu) endometrial polip, \%1,6'sında (2 olgu) subseptum, \%1,6'sında diğer patolojiler (1 olguda submukoz myom, 1 olguda plasental bölge nodülü) gözlendi.

\section{Grupların gebelik sonuçları}

Çalışmamızda histeroskopi sonrası toplam altı olguda spontan gebelik gelişti. Toplamda tüm olgular ele alındığında $\mathrm{H} / \mathrm{S}$ ve endometrial küretaj sonrası \%37,7 hCG pozitifliği (95/252), \%35,3 klinik gebelik (89/252), \%9,1 (23/252) klinik gebelik kaybı (21 olgu 1-2. tm gebelik kaybı, 2 olgu 3. tm gebelik kaybı) ve $\% 26,2$ canlı doğum (66/252) oranları saptandı. Gruplar arası karşılaştırmada hCG pozitifliği, klinik gebelik, klinik gebelik kaybı ve canlı doğum oranları arasında anlamlı bir farklılık izlenmedi (Tablo-3).

Tekrarlayan implantasyon başarısızlığı olan 124 olgu ayrıca ele alındığında, H/S ve endometrial biyopsiden embriyo transferine geçen süre açısından grupların gebelik oranları arasında yine anlamlı bir farklılık gözlenmedi (Tablo-4).

\section{TARTIŞMA}

IVF öncesinde endometrial hasar oluşturmanın gebelik oranlarına etkisiyle ilgili çalışmaların sonuçları tartışmalıdır. 2015'te yayınlanan Cochrane meta-analizinde konuyla ilgili 14 randomize kontrollü çalışma sonuçları ele alınmış ve IVF siklusundan önceki siklusta endometrial hasar oluşturmanın orta düzeyde kanıtla klinik gebelik ve canlı doğum oranlarında artışla ilişkili bulunduğu, oosit toplama günü yapılan uygulamanın ise klinik gebelik ve canlı doğum oranlarında azalmayla ilişkili göründüğü bildirilmiştir (6). Yakın zamanda yayınlanan ve konuyla ilgili 14 randomize kontrollü çalışma içeren (2537 olgu) bir başka meta-analizde klinik gebelik ve canlı doğum üzerine olası etkinin değerlendirilmesi amacıyla; i) ilk IVF öncesi, ii) bir tamamlanan siklus ve ardından dondurulmuşçözülmüş embriyo transferi sonrası uygulama ve iii) en az iki tam siklus sonrası uygulanan olgular ayrı gruplar halinde ele alınmıştır. Ele alınan 
çalışmaların çoğunda endometrial hasar oluşturma pipelle ile yapılmıştır. Dahil edilen çalışmalardaki belirgin klinik heterojenite nedeniyle sadece bir tamamlanan siklus ve dondurulmuş-çözülmüş embriyo transferi sonrası olgulardaki sonuçların meta-analize alınabildiği bildirilmiştir. $\mathrm{Bu}$ grubun analiz sonucunda endometrial hasar oluşturma ve kontrol grubu arasında klinik gebelik ve canlı doğum oranları açısından farklııı bulunmadığı bildirildi. Diğer iki grubu içeren randomize kontrollü çalışmaların sonuçlarının olumlu, olumsuz ya da etkisi olmadığı yönünde olduğu, bu gruplar için yapılan alt grup analizlerinde de canlı doğum oranlarının farklı olmadığı ancak klinik gebelik oranlarında endometrial hasar oluşturma grubunda anlamlı artış gösterdiği bildirildi (7). Yine 2019 yılında yayınlanan diğer bir meta-analizde de en az bir başarısız IVF siklusu sonrası endometrial hasar oluşturmanın etkinliği açısından konuyla ilgili 10 randomize kontrollü çalışma ele alındı (8). Sonuçta toplam olgular içinde uygulama grubunda daha yüksek klinik gebelik ve canlı doğum oranları bulunduğu ancak iki veya daha fazla IVF başarısızlığı, ileri yaş grubu gibi alt gruplarda anlamlı bir artış izlenmediği bildirildi. Endometrial hasar oluşturmanın etkinliği ve varsa hangi grupta olduğuyla ilgili ileri çalışmalar gerektiği bildirilmiştir. Araştırmacıların 2020 yılında yayınlanan güncellenmiş metaanalizlerinde toplamda 3016 olguyu içeren 17 çalışma ele alınmıştır. Benzer olarak uygulamanın klinik gebelik ve canlı doğum oranları üzerine olumlu etki gösterdiği, iki başarısız IVF siklusu olan olguları içeren alt grup analizinde ise gruplar arasında canlı doğum oranları açısından farklılık gözlenmediği bildirilmiştir. Yine genç yaş olgu grubunda uygulamanın etkinliğinin daha belirgin olduğu vurgulanmıştır (9). Uygulamanın etkinliğinin belirgin olabileceği optimal popülasyon ve uygulama şeklinin halen tam bilinmediği ve tartışmalı olduğu bildirilmiştir (9). Yakın zamanda yayınlanan retrospektif bir çalışmada en az iki IVF siklusu sonrası (ortalama 4,5 siklus) açıklanamayan tekrarlayan implantasyon başarısızıı̆ı olan olgularda IVF öncesi geç proliferatif ve orta luteal fazda pipelle endometrial hasar oluşturmanın uygulama yapılmayan kontrollere göre klinik gebelik ve canlı doğum oranlarında anlamlı oranda artışla ilişkili bulunduğu ve uygulamanın gebelik oluşması üzerine bağımsız bir faktör olabileceği öne sürülmüştür. Araştırıcılar bulgularının geniş bir prospektif randomize çalışma ile doğrulanması gerektiğini de vurgulamışlardır (12).

Uterus kavitesinin doğrudan gözlenmesi ve olası patolojilerin aynı anda tedavi şansı nedeniyle $\mathrm{H} / \mathrm{S}$ uterus kavitesinin değerlendirilmesinde altın standart kabul edilen yöntemdir (1). IVF olgularında şüpheli bir bulgu olmasa da H/S'de intrauterin bir patoloji ile karşılaşma olasılığına dikkat çekilmiştir (13-17). Bizim çalışmamızda da ele aldığımız ve tekrarlayan implantasyon başarısızlığı nedeniyle $\mathrm{H} / \mathrm{S}$ uyguladığımız olguların yaklaşık \%25'inde çoğunluğu endometrial polip olmak üzere daha önce fark edilmemiş bir uterin patoloji saptadık.

IVF öncesi rutin $\mathrm{H} / \mathrm{S}$ uygulanmasının reprodüktif sonuçları olumlu yönde etkileyebileceği sonucuna varan meta-analiz sonuçlarının $(3,4)$ yanı sıra rutin $\mathrm{H} / \mathrm{S}$ uygulamasının herhangi bir etkisinin bulunmadığı yönündeki yakın zamanlı çok merkezli, randomize kontrollü iki çalışmanın sonuçları oldukça dikkat çekmiştir (18-19). Konuyla ilgili 2019 'da yayınlanan Cochrane metaanalizinde bu iki çalışmanın da dahil edildiği ve IVF öncesi H/S etkinliğini araştıran 10 çalışma ele alınmış ve sonuçta uygulamanın klinik gebelik (RR 1.32, 95\% Cl 1.20-1.45, 10 randomize kontrollü çalışma) ve canlı doğum oranlarında artışla ilişkili olabileceği (RR 1.26, 95\% Cl 1.11$1.43 ; 6$ randomize kontrollü çalışma) ancak eldeki kanıtın düşük kalitede olduğu ve yanlılık riski düşük olan iki çalışmanın analizinde canlı doğum açısından bir faydanın gösterilmediği de bildirilmiştir. İki veya daha fazla IVF başarısızığı olan alt grup analizinde histeroskopi klinik gebelik (4 randomize kontrollü çalışma) ve canlı doğumda (3 randomize kontrollü çalışma) artışla ilişkili bulunmuştur (5). Cao ve ark.'larının 2018'de yayınladıkları, tekrarlayan implantasyon başarısızlığı olgularını içeren altı çalışmanın meta-analizinde de IVF öncesi H/S uygulanması klinik gebelik ve canlı doğum oranlarında anlamlı artışla ilişkili bulunduğu bildirildi (4).

Tekrarlayan implantasyon başarısızlığı olan olgularda H/S'ye ek olarak endometrial hasar oluşturmanın gebelik oranlarına katkısıyla ilgili çalışmalar da yayınlanmıştır. Yakın zamanda yayınlanan randomize kontrollü bir çalışmada, 40 yaş altı tekrarlayan implantasyon başarısızlığı olan ve bir önceki siklusta ofis H/S sırasında standardize edilmiş şekilde endometrial hasar oluşturulan 124 olgu ile herhangi bir girişim yapılmayan 115 kontrol olgunun gebelik sonuçları karşılaştırılmıştır. Çalışma grubunda 
implantasyon, klinik gebelik ve canlı doğum oranlarının kontrollere göre anlamlı oranda yüksek bulunduğu bildirilmiştir (20). Nonrandomize prospektif bir başka çalışmada da tekrarlayan implantasyon başarısızlığı olan olgularda bir önceki siklusta H/S sırasında standardize edilmiş yolla endometrial hasar oluşturulan grupta (51 olgu) kontrollere göre (52 olgu) canlı doğum oranlarının daha yüksek bulunduğu rapor edilmiştir (21). Retrospektif bir diğer çalışmada da bir önceki siklusta ofis $\mathrm{H} / \mathrm{S}$ sırasında endometrial hasar oluşturma (monopolar iğne ile) (171 olgu) yapılan grupla, sadece H/S uygulanan grubun (174 olgu) IVF sonuçları karşılaştırılmış ve çalışma grubunda implantasyon, klinik gebelik ve devam eden gebelik oranlarının daha yüksek bulunduğu bildirilmiştir (22). Berntsen ve ark.'larının randomize kontrollü bir çalışmalarında ise en az bir başarısız IVF/ICSI siklusu olan olgular ele alınmıştır. IVF siklusundan önceki siklusta H/S yanı sıra endometrial biyopsi uygulanan olgularda $(n=92)$, uygulama yapılmayan kontrol grubuna $(n=92)$ göre reprodüktif sonuçlar açısından istatistiksel olarak anlamlı bir fark bulunmadığı ancak sınırlı olgu sayısı nedeniyle yöntemin etkinliği açısından net bir yorum yapılamadığı ve ileri çalışmalara intiyaç olduğu da bildirilmiştir (23).

Tartışmada yer alan çalışmaların çoğunluğunda uygulamalar IVF siklusundan bir önceki veya yakın dönemdeki sikluslarda (1-3 ay) yapılmıştır. IVF öncesi $\mathrm{H} / \mathrm{S}$ ile ilgili optimal bir süre tanımlanmamıştır. Konuyla ilgili retrospektif bir çalışmada IVF öncesi H/S ile polipektomi yapılan 487 hastada prosedür ile takip eden IVF siklusu arası geçen süre açısından reprodüktif sonuçlar karşılaştırılmıştır. Takip eden siklus sonrası IVF, iki veya üç siklus sonrası IVF ve üç siklustan daha geç IVF uygulamanın implantasyon, klinik gebelik, düşük ve canlı doğum oranlarında bir farklılık yaratmadığı sonucu bildirilmiştir (24).

\section{SONUÇ}

Çalışmamızda IVF öncesi H/S ve probe küretajla endometrial biyopsi yaptığımız olgularda uygulama ile embriyo transferi arası geçen sürenin gebelik oranlarına etkisini araştırdık. Çalışmamızda endometrial hasar oluşturma önceki çalışmalardan farklı olarak probe küretajla gerçekleştirildi. Çalışmamızda prosedürler arası geçen süre açısından 1 ay ile $>6$ ay periyodu arası beş ayrı grupta gebelik sonuçları değerlendirilmiştir. Çalışmamızın retrospektif olması bir kısıtııık oluşturmakla birlikte, ele alınan geniş olgu grubunun değerlendirilmesi, prosedürler arası sürenin gebelik, klinik gebelik, gebelik kaybı ve canlı doğum oranları üzerine anlamlı bir farklılık yaratmadığını gözlemleyebilmemizi sağlamıştır. Sonuç olarak embriyo transferinin ardışık siklusta yapılması ile daha ilerideki sikluslarda yapılması anlamlı farklılığa yol açmayabilir. $\mathrm{H} / \mathrm{S}$ ve endometrial biyopsinin olumlu bir katkısı varsayılırsa bu katkı uzun zamana yayılım gösteriyor olabilir.

Çıkar çatışması: Yazarlar çıkar çatışması beyan etmemişlerdir.

\section{Kaynaklar}

1. Pundir J, El Toukhy T. Uterine cavity assessment prior to IVF. Womens Health (Lond). 2010 Nov; 6 (6): $841-7$

2. Di Spiezio Sardo A, Di Carlo C, Minozzi S, et al. Efficacy of hysteroscopy in improving reproductive outcomes of infertile couples: a systematic review and meta-analysis. Hum Reprod Update. 2016 Jun; 22 (4): 479-96.

3. Pundir J, Pundir V, Omanwa K, Khalaf Y, El-Toukhy T. Hysteroscopy prior to the first IVF cycle: a systematic review and meta-analysis. Reprod Biomed Online. 2014 Feb; 28 (2): 151-61.

4. Cao H, You D, Yuan M, Xi M. Hysteroscopy after repeated implantation failure of assisted reproductive technology: A meta-analysis. J Obstet Gynaecol Res. 2018 Mar; 44 (3): 365-73.

5. Kamath MS, Bosteels J, D'Hooghe TM, et al. Screening hysteroscopy in subfertile women and women undergoing assisted reproduction. Cochrane Database Syst Rev. 2019 Apr 16; 4: CD012856.

6. Nastri CO, Lensen SF, Gibreel A, et al. Endometrial injury in women undergoing assisted reproductive techniques. Cochrane Database Syst Rev. 2015 Mar 22; (3): CD009517.

7. Van Hoogenhuijze NE, Kasius JC, Broekmans FJM, Bosteels J, Torrance HL. Endometrial scratching prior to IVF; does it help and for whom? A systematic review and meta-analysis. Hum Reprod Open. 2019 Jan 29; 2019 (1): hoy025.

8. Sar-Shalom Nahshon C, Sagi-Dain L, Wiener-Megnazi Z, Dirnfeld M. The impact of intentional endometrial injury on reproductive outcomes: a systematic review and meta-analysis. Hum Reprod Update. 2019 Jan 1; 25 (1): 95-113. 
9. Nahshon C, Sagi-Dain L, Dirnfeld M. The impact of endometrial injury on reproductive outcomes: results of an updated meta-analysis. Reprod Med Biol. 2020 Sep 17; 19 (4): 334-49.

10. Siristatidis $C$, Vrachnis N, Vogiatzi $P$, et al. Potential pathophysiological mechanisms of the beneficial role of endometrial injury in in vitro fertilization outcome. Reprod Sci. 2014 Aug; 21 (8):955-65.

11. Gnainsky Y, Granot I, Aldo PB, et al. Local injury of the endometrium induces an inflammatory response that promotes successful implantation. Fertil Steril. 2010 Nov; 94 (6): 2030-6.

12. Bar G, Harlev A, Alfayumi-Zeadna S, Zeadna A, Bord I, Har-Vardi I, Lunenfeld E, Levitas E. Recurrent implantation failure: which patients benefit from endometrial scratching prior to IVF? Arch Gynecol Obstet. 2020 Mar;301(3):817-22.

13. Pabuçcu EG, Yalçın I, Bodur T, Çağlar GS, Pabuçcu R. Impact of Office hysteroscopy in repeated implantation failure: Experience of a single center. J Turk Ger Gynecol Assoc. 2016 Dec 1; 17 (4): 197-200.

14. Hosseini MA, Ebrahimi N, Mahdavi A, et al. Hysteroscopy in patients with repeated implantation failure improves the outcome of assisted reproductive technology in fresh and frozen cycles. J Obstet Gynaecol Res. 2014 May; 40 (5): 1324-30.

15. Kilic Y, Bastu E, Ergun B. Validity and efficacy of Office hysteroscopy before in vitro fertilization treatment. Arch Gynecol Obstet. 2013 Mar; 287 (3): 577-81.

16. Gao M, Sun $Y$, Xie H, Fang S, Zhao X. Hysteroscopy prior to repeat embryo transfer may improve pregnancy outcomes for asymptomatic women with repeated implantation failure. J Obstet Gynaecol Res 2015; 41: 1569-76.

17. Bozdag G, Aksan G, Esinler I, Yarali H. What is the role of Office hysteroscopy in women with failed IVF cycles? Reprod Biomed Online. 2008 Sep;17 (3): 410-5.

18. Smit JG, Kasius JC, Eijkemans MJC, et al. Hysteroscopy before in-vitro fertilisation (inSIGHT): a multicentre, randomised controlled trial. Lancet. 2016 Jun 25; 387 (10038): 2622-29.

19. El-Toukhy T, Campo R, Khalaf $Y$, et al. Hysteroscopy in recurrent in-vitro fertilisation failure (TROPHY): a multicentre, randomised controlled trial. Lancet. 2016 Jun 25; 387 (10038): 2614-21.

20. Gürgan T, Kalem Z, Kalem MN, Ruso H, Benkhalifa M, Makrigiannakis A. Systematic and standardized hysteroscopic endometrial injury for treatment of recurrent implantation failure. Reprod Biomed Online. 2019 Sep; 39 (3): 477-83.

21. Siristatidis C, Kreatsa M, Koutlaki N, Galazios G, Pergialiotis V, Papantoniou N. Endometrial injury for RIF patients undergoing IVF/ICSI: a prospective nonrandomized controlled trial. Gynecol Endocrinol. 2017 Apr; 33 (4): 297-300.

22. Seval MM, Şükür YE, Özmen B, et al. Does adding endometrial scratching to diagnostic hysteroscopy improve pregnancy rates in women with recurrent in-vitro fertilization failure? Gynecol Endocrinol. 2016 Dec; 32 (12): 957-60.

23. Berntsen S, Hare KJ, Løssl K, Bogstad J, Palmø J, Prætorius L, Zedeler A, Pinborg A. Endometrial scratch injury with office hysteroscopy before IVF/ICSI: A randomised controlled trial. Eur J Obstet Gynecol Reprod Biol. 2020 Sep; 252: 112-7.

24. Pereire N, Amrane S, Estes JL, et al. Does the time interval between hysteroscopic polypectomy and start of in vitro fertilization affect outcomes? Fertil Steril. 2016 Feb; 105 (2): 539-44. 